Silva Gomzi Praprotnik

Višja strokovna šola za gostinstvo in turizem Bled silva.praprotnik@vgs-bled.si
UDK 640.4(497.4):811.131.1-054.5

DOI: $10.4312 /$ vestnik.8.251-258

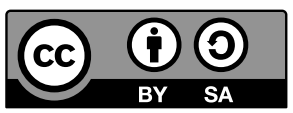

\title{
SLOVENSKA GOSTINSKA PONUDBA IN ITALIJANSKI GOSTI
}

Na začetku 21. stoletja so turistične destinacije, o katerih smo nekoč samo sanjarili ali si jih le želeli obiskati, postale hitro dosegljive in lahko dostopne. Razvile so se nove oblike turizma v novih razmerah, ki od turističnih delavcev zahtevajo več različnih spretnosti in veščin, večjo prilagodljivost in hitrejše odzivanje na nenadne dogodke v lokalnem in širšem okolju. Poznavanje jezika, računalniško znanje, povezovanje znanj z različnih področij pomagajo priti do »interakcije idej, dialoga, ki naj bi v svetu globalizacije pomagal presegati meje časa, prostora in kultur in zlasti vzpostavljati povezave med ljudmi, med področji znanja, med izkušnjami prejšnjih generacij in težnjami prihodnjih« (Alexander v Marentič Požarnik, Plut Pregelj, 2009, str. 19).

Kot profesorica italijanskega jezika v šoli, ki izobražuje študente za delo v turističnih dejavnostih, imam priložnost spoznavati prijetne in neprijetne plati dela v hotelirstvu, gostinstvu in velneških centrih, saj šola v okviru sodelovanja s turističnim gospodarstvom organizira tudi tečaje jezika stroke. Ob tem lahko neposredno pridobivamo izkušnje s področja uporabe jezika, civilizacijskih, kulturnih in drugih značilnosti gostov, s katerimi turistični in gostinski delavci ter delavci v velneških centrih prihajajo v stik. V tem članku sem svoja opažanja in spoznanja omejila na področje gostinstva.

\section{2}

\section{TURIZEM KOT GOSPODARSKA PANOGA}

»Potovanje je jezik miru«, je na blejskem strateškem forumu letos septembra izjavil generalni sekretar Svetovne turistične organizacije Taleb Rifai in nadaljeval: »Turizem je prava globalno mirovna industrija. Kajti nemogoče je sovražiti nekoga, ki ga poznaš osebno, ki si ga gostil ali pa je gostil tebe.« Poudaril je tudi, da Slovenija postavlja turizem za nacionalno in mednarodno prioriteto za doseganje trajnostnega razvoja, miru in varnosti ter pozval druge države, da ji sledijo pri tem. V intervjuju v časniku Delo je dodal, da je Slovenija ena najhitreje rastočih turističnih destinacij na svetu in poudaril potrebo po odprtosti meja tudi v času naraščajočih terorističnih groženj. Odprtost meja vsaj zaenkrat ne predstavlja problema 
v turističnem gospodarstvu in turizem še vedno ostaja ena od najhitreje rastočih panog tako na svetovni kot tudi nacionalni ravni. V preteklem letu je svetovni turizem dosegel 4,4\% rast, evropski turizem $5 \%$, slovenski turizem pa kar $12,3 \%$ rast mednarodnih prihodov. Vendar so statistike le ena plat uspešnosti panoge, kajti v sedanjem kriznem času se vse bolj poudarja pomen varnosti in trajnostnega razvoja in Slovenija se na evropskem in svetovnem turističnem zemljevidu predstavlja kot zelena, aktivna, zdrava in varna destinacija.

\subsection{Turizem kot gospodarska panoga v Sloveniji}

Turizem v Sloveniji predstavlja veliko poslovno priložnost, saj je s 40 \% izvoza največji izvoznik storitev in zagotavlja $13 \%$ vseh delovnih mest (103.500), ki so neposredno in posredno povezana s turizmom. Po podatkih Slovenske turistične organizacije (STO) je bilo v letu 2015 zabeleženih več kot 3,9 milijona prihodov (11,5\% več kot 2014) in prvič tudi več kot 10 milijonov prenočitev (7,8 \% več kot 2014) turistov v Sloveniji, v hotelih pa prvič nad 6 milijonov prenočitev. Največ turističnih prenočitev je bilo zabeleženih $v$ Piranu, Ljubljani in na Bledu, med vrstami občin pa so prevladovale zdraviliške. Največ prenočitev je bilo s strani Italijanov, Avstrijcev, Nemcev, Hrvatov in Nizozemcev.

\section{3}

\section{ITALIJANI V SLOVENIJI}

Največ prenočitev so v letu 2015 tako kot leto poprej prispevali turisti iz Italije (15,9\%, v letu 2014 15,8 \%). Italijani, ki prihajajo v Slovenijo, so največkrat tisti iz bližnjih severnoitalijanskih pokrajin, kot so Veneto, Furlanija Julijska Krajina in Emilia Romagna, torej iz pokrajin, ki se jih kriza ni občutneje dotaknila in kjer živi kar $30 \%$ vseh italijanskih turistov, ki si za počitnice izberejo tujino. Pomembna je zlasti bližina Furlanije Julijske krajine, od koder se dvakrat letno za vsaj dve nočitvi odpravi kar 34 \% prebivalstva,

\subsection{Italijani kot gosti}

Hrana je pomemben del materialne kulture vsakega naroda, saj odraža vsakdanje življenje, ritem letnih časov, podnebje, okolje, kmetijske pridelke in zgodovinska obdobja. In prav hrana je eden najpomembnejših dejavnikov za vsakega Italijana, tudi za tistega, ki se odpravi na turistična potepanja.

Kakšne so značilnosti italijanskih gostov, kadar je govora o hrani? V italijanski kulturi je hrana prisotna na vsakem koraku. Mnogi pogovori se zato vrtijo okoli hrane, o tem, kaj in kako kuhati, o tem, kako kuha mama ali kako je kuhala stara mama in kakšna morata ali bi morala biti vonj in okus italijanskih jedi. Mama jih je naučila, da je italijanska kuhinja najboljša na svetu in zato tudi na potovanjih po svetu iščejo testenine, pico 
in kapučino in so razočarani, ko odkrijejo, da preostali svet ne deli v celoti njihovega mnenja glede njihovih najljubših jedi.

Pregovor » Ko si v Rimu, počni to, kar počnejo Rimljani« za mnoge evropske turiste in za Italijane še posebno ne velja vedno. Prenekateri italijanski turist želi tudi na potovanjih v tujih deželah najti duha svojega okolja, jesti italijansko hrano, imeti italijanskega vodnika in kar najbolj ohraniti domače, italijanske navade. Italijanski gost je torej glede hrane izrazito lokalpatriot.

Izkušnje gostinskih in turističnih delavcev v Sloveniji, kot sem povzela iz pogovorov z njimi na raznih jezikovnih izpopolnjevanjih, kažejo na to, da je značilen italijanski gost zelo priljubljen in dobrodošel, ker je simpatičen, dokaj potrpežljiv, prijazen, vljuden, zanimata ga predvsem dobra kuhinja in dobra zabava. V Sloveniji ima od hrane najraje domače njoke, dober pršut, okusno meso, mesnine, ribe, palačinke, dobro vino, prekmursko gibanico in še kaj. Ceni okusnost in pristnost jedi slovenske kuhinje, ki lahko razvajenim italijanskim gostom veliko ponudi.

Težko pa se sprijazni z nekaterimi pogostimi napakami, ki jih delajo gostinski delavci v Sloveniji pri pripravi in ponudbi tipičnih italijanskih jedi. Pri nekaterih jedeh ga moti mešanje okusov oziroma začimb (vsaka jed naj ima točno določene začimbe, ki dajejo jedi točno določen okus), ni mu všeč zaporedje jedi (ribji predjedi naj ne sledi meso in obratno), preveč je različnih sestavin, zaradi česar se prvotni okus in vonj jedi izgubita in od originalne jedi včasih ostane samo še ime.

\subsection{Jezikovna komponenta pri obisku italijanskih gostov}

Tudi jezik nam skozi imena posameznih jedi in njihovih sestavin kaže vpetost ljudi nekega področja v skupnost, ki je mešanica različnih kultur, tradicij, gastronomij in krajevnih značilnosti. Italijanski gost je po tradiciji jezikovno manj spreten, v večini primerov ne govori nobenega tujega jezika, je pa zelo dobrohoten pri pregledovanju jedilnih listov, kjer včasih mrgoli pravopisnih in strokovnih napak, kadar so ti prevedeni v italijanski jezik.

Besedila, s katerimi gostje najpogosteje prihajajo v stik, so meniji, razna navodila, prospekti, obvestila, hišni redi itd. Pri svojem delu prevajalke sem pri prevajanju menijev v italijanščino pogosto naletela na različne primere prevodov ali terminov, ki so se uporabljali pri jedeh in ki potrebujejo dodatno razlago tistega, ki hrano ponudi. Naj navedem le nekaj primerov, kjer mora strežno osebje uporabiti svoje znanje italijanščine, da natančneje razloži :

a) način priprave ali prisotnost tujih sestavin (npr. po ljubljansko ali po istrsko, krompir berry (kuhan mladi krompir s čebulo in slanino), hladni wellington (goveji biftek v listnatem testu), sarme, koruzni blini, juha miso, kvinoja, kuskus);

b) tipične slovenske jedi, ki jih je praviloma treba opisati (zaseka, meso iz tunke, ajdova kaša, čompe s skuto (kuhan krompir z omako iz skute in kisle smetane, kranjska 
klobasa, kraški toč (na olju prepražene rezine pršuta, prelite s teranom), prekmurska gibanica, pohorska omleta), ker so značilne le za slovenski prostor;

c) jedi, opisane s kopičenjem besed in pleonazmi, ki niso v tesni zvezi z gastronomijo (na kraški posteljici, v družbi z medom in figovo marmelado, harmonija slovenskih domačih sladoledov, grmada, krompirjev mož, matevž);

d) tuje besede, kot so na primer espuma (skupen izraz za pene na osnovi vode ali maščobe ter emulgatorja ali gelifikanta, ki jih naredimo s pomočjo steklenice s potisnim plinom NO2) ali gremolata (omaka iz limonine lupinice, česna, peteršilja in oljčnega olja).

Primeri jedilnikov v slovenskih lokalih torej kažejo na to, da je znanje tujega, $v$ tem primeru italijanskega jezika, pomembno in nujno pri komunikaciji z gostom, saj navedba jedi v jedilnem listu velikokrat potrebuje dodatno razlago.

Zanimiv primer so lokali s t. i. italijansko kuhinjo. Že v originalu, torej v slovenski ponudbi, je včasih zaznati nepoznavanje te kuhinje, sestave jedilnika, vrstnega reda jedi in pijač itd. Na jedilnikih je pogosto najti:

- jezikovne napake, kot so buffalo mozzarela, pršut doc San Daniele, sir Pekorino, olive gigante, radič trevisiano, gran padana, kapucino, kjer bi bilo bolje napisati mocarela iz bivoljega mleka, pršut s kontroliranim poreklom iz San Daniele, ovčji sir, oljke velikanke, treviški radič, sir za ribanje Grana Padano ali padski parmezan, kapucinar;

- $\quad$ vsebinske napake, kot npr. slani fileti, gamberi namesto slani fileti inčunov in kozice;

- $\quad$ strokovne napake, kjer so trde testenine nadomestile italijansko delitev na pasta fresca in pasta secca (sveže in posušene testenine), pijači aperol in aperol spritz sta se znašli med digestivi, Martini bianco in rosso med desertnimi vini, v goveji juhi so se znašli široki rezanci $v$ jedi zuppa di manzo con tagliatelle, kar pomeni »široki široki rezanci« v goveji juhi, glede na to, da so tagliatelle že sami po sebi ime za široke rezance, ki se praviloma jedo z bolonjsko omako, nikakor pa ne v goveji juhi, široki rezanci so postali še bolj široki tudi v jedi tagliatelle larghe alla carsica (široki široki rezanci po kraško) in podobno.

\section{ENOGASTRONOMSKI TURIZEM}

Tudi v Sloveniji se vse bolj širijo nove oblike turizma, med katerimi izstopajo kulturni, športni, poslovni, zdraviliški, pa tudi enogastronomski turizem, ki poleg tipičnih jedi in pijač teritorija poudarja potrebo po splošnem odkrivanju nekega območja in njegovih kulturnih, umetnostnih, zgodovinskih in naravnih danosti. Enogastronomski turist je pripravljen premikati se po območju, stopati v stik s proizvajalcem, degustirati izdelke v kraju, kjer so ti nastali, se z njimi oskrbeti in to je izkušnja, s pomočjo katere območje ne samo spoznava, ampak ga tudi občuti in doživlja kot edinstveno, novo in neponovljivo. 
Kulinarična ponudba kot pomemben del turistične ponudbe je za italijanskega gosta, ki odkriva slovensko deželo, lahko cilj in sredstvo, razlog za potovanje in orodje za obogatitev turističnega doživetja, vendar pa ta gost, ki je pregovorno precej zgovoren, vedoželjen, dobrohoten, lahko naleti na nekatere težave.

\section{KOMUNIKACIJA MED ITALIJANSKIMI GOSTI IN SLOVENSKIMI TURISTIČNIMI DELAVCI}

S kakšnimi problemi se v medsebojni komunikaciji torej srečujeta slovenski gostinski ali turistični delavec in italijanski gost v notranjosti države, npr. na Bledu, v Kranjski Gori, Ljubljani ali v številnih zdraviliških krajih, ki jih Italijani že dolga leta in desetletja radi obiskujejo? Na podeželju, ki ga odkrivajo zadnje čase?

$\mathrm{Na}$ Obali in Goriškem italijanski jezik v komunikaciji z italijansko govorečimi gosti ne predstavlja problema, $v$ notranjosti Slovenije pa sta srečevanje in delo z italijanskimi gosti pogosto otežena zaradi jezika. Študija, ki so jo leta 2007 objavili Francesco Palumbo, Paola Marzilli in Maura Montironi, navaja prav komunikacijo kot tisti glavni vir, ki zmore povečati turistično konkurenčnost nekega teritorija.

Obisk italijanskih gostov je večinoma omejen na poletni, avgustovski čas in na decembrske počitnice, zato osebju v prenočitvenih in gostinskih lokalih manjka priložnosti, da bi svoje znanje jezika izpopolnili in nadgradili. Naši kuharji in natakarji, zlasti tisti v notranjosti države, tudi zaradi neznanja ali pomanjkljivega znanja jezika niso zmožni komunikacijskih veščin, s katerimi bi lahko ponujali avtentične ali vsaj tipične jedi, spraševali o preferencah, aktivno spodbujali k poskušanju in naročanju ter upoštevanju različnosti.

Zadovoljen zaposleni sicer ve, da tudi prijazen pozdrav, nenarejen smehljaj, ljubezniva gesta pri pomoči gostu delajo čudeže, vendar pa je znanje jezika v večini primerov pri delu z gosti nujno potrebno. Tu je treba izpostaviti pomanjkanje posluha za izobraževanja, tudi jezikovna, pri vodstvenih delavcih turističnih in gostinskih objektov, saj vodstvo kreira atmosfero $\mathrm{v}$ nekem kolektivu in preko zaposlenih zaznava potrebe po dodatnih spretnostih in veščinah. Samo vodstvo, ki je sposobno preseči racionalni pristop in ki poudarja tudi čustveno inteligenco in znanje jezikov kot del svojega vodenja, lahko vpliva na to, da nekdo z ljudmi in ob ljudeh enostavno več zna in zmore. Motiviranost za učenje, ki je tudi posledica nizkih dohodkov, je majhna, zaposleni so (pre)malo ambiciozni, prehitro se zadovoljijo $\mathrm{z}$ doseženim, ne želijo spoznavati novih okolij in novih smernic v poklicu. Problematiko je treba, vsaj tako menijo zaposleni sami in tudi nekateri vodilni ljudje, ki delajo $\mathrm{v}$ teh panogah, rešiti sistemsko: treba je najti zakonsko podlago za boljše nagrajevanje ljudi, ki so zaposleni v gostinstvu in turizmu, saj so plačila sedaj sramotno nizka, poudariti je treba pomen izobrazbe, saj sedanji sistem omogoča delo v gostinstvu tudi tistim, ki nimajo ustrezne strokovne izobrazbe, treba je vrniti ugled poklicem v storitvenih dejavnostih, saj je nekdaj cenjeni poklic natakarja, vodje strežbe sedaj 
čisto razvrednoten, dodatna znanja jezikov, poznavanja vin, priprave jedi in pijač pred gostom ipd. bi morala biti dodatno nagrajena, odpraviti bi bilo treba uravnilovko in uvesti stimulativne nagrade, denarne ali drugačne oblike nagrajevanj za gospodarno ravnanje s hrano in pijačo, za posebno prijazen odnos do gostov in še kaj bi lahko našteli. Večina problemov na tem področju je sicer povezana s sistemskimi rešitvami, nekatere rešitve pa bi vodstveni delavci v gostinstvu lahko uvedli in uporabljali tudi sami.

\section{PRILOŽNOSTI TURISTIČNIH DELAVCEV IN KAJ LAHKO STORIMO SAMI?}

Kaj lahko storimo delavci v gostinstvu in turizmu že sami? Čeprav so osnova italijanske kuhinje testenine, kar ponazarja celo reklama za testenine Barilla, ki pravi »dove c'è Barilla c'è casa« (dom je tam, kjer je Barilla), si Italijani na potovanjih vendar želijo pokusiti tudi lokalne jedi.

Namesto potvorjenih, tako imenovanih italijanskih jedi je morda bolj smiselno ponuditi originalne tipične slovenske jedi in posebno penzionskim gostom domačo lokalno hrano, ki pa jo je potrebno primerno predstaviti in ponuditi. Italijanskim gostom, ki pogosto vrednotijo svoja potovanja in raznovrstna doživetja prav s hrano, ki jo pri tem okušajo, saj cenijo pristnost in okusnost, in seveda tudi drugim, bi $\mathrm{v}$ ta namen lahko organizirali predstavitve lokalnih in regionalnih kuhinj. Vse pa je treba ustrezno predstaviti, z zgodbo vpeti $\mathrm{v}$ prostor, kjer so jedi in pijače nastale in povezati $\mathrm{z}$ animacijo in drugimi spremljevalnimi dejavnostmi.

Sodelovanje s turističnimi delavci, kulinaričnimi strokovnjaki in z lokalnimi proizvajalci hrane bi bilo lahko stalna dopolnitev gastronomske ponudbe, zlasti pri gostih, ki v hotelu ali penzionu ostajajo več časa. Poudarjati je nujno tudi nekatere kulturno-civilizacijske razlike, saj mnogi slovenski gostinski delavce ne vedo, da Italijani testenin ne jedo z žlico, še manj z nožem, da pa jih je treba pravilno nalomiti in skuhati al dente, da se Italijanom kapučino po kosilu zdi nekaj nezaslišanega in jim ga zato ne ponujajmo, da je digestiv po kosilu skoraj obvezen itd.

Zato smo spet na začetku: naloga vseh nas, ki smo kakorkoli povezani s turizmom, je gosta tudi vzgajati in izobraževati, zato pa moramo veliko znanja imeti tudi sami. Pomembno je tudi to, da večkrat in vedno znova vodstvenim delavcem $v$ gostinskih in turističnih obratih izražamo potrebo po izobraževanju, motiviranosti za delo in spoznavanju novega. Le tako bomo sami poskrbeli za svoj razvoj, obenem pa tudi višjo raven znanja jezikov in ostalega znanja, da bomo lahko z gosti ustvarili še boljši odnos. 
Hrana in pijača ter ponudba le teh sta tudi priložnost za komunikacijo med ljudmi, ki prihajajo iz različnih socialnih, religioznih, generacijskih in drugih življenjskih okolij, medsebojno sporazumevanje pa je hkrati lahko odlična priložnost za promocijo in spoštovanje kulturne in gastronomske raznolikosti.

Zlasti pri italijanskih gostih je hrana zagotovo tista, po kateri si bodo kraj, restavracijo ali pokrajino zapomnili in o njej pripovedovali tudi ostalim. Dober lokal, dobra hrana, prijazno osebje so magnet za italijanske goste, ki bodo kasneje pripeljali s seboj še svoje prijatelje, družino in poslovne partnerje.

Posebno pozornost moramo zato namenjati turističnim delavcem, ki znajo svojo strokovnost nadgraditi z veščinami, ki jim omogočajo tudi promoviranje, »prodajo« in pravo vrednotenje. Pri tem ima pomembno vlogo znanje jezika, saj prav jezikovna usposobljenost daje več priložnosti in zmožnosti, da te veščine prenesejo na različna področja v zasebnem in poklicnem življenju, s čimer se lahko tudi osebnostno in strokovno izpopolnjujejo, še zlasti, če so tudi primerno plačani in če so odnosi v kolektivu dobri.

Nevednost prinaša netoleranco, večjezičnost in medkulturni dialog v vseh oblikah in na vseh področjih pa lahko bistveno prispevata $\mathrm{k}$ odpravljanju predsodkov, neznanja in strahu pred neznanim. Tudi v kulinariki in turizmu.

\section{LITERATURA}

GOMZI PRAPROTNIK, S. (2009) Poučevanje italijanščine kot jezika stroke v turističnih podjetjih v okviru predmeta Strokovna terminologija v italijanščini na VGŠ Bled. Portorož, Konferenca: Management, izobraževanje in turizem

HÖHMANN, D. A./S. SANGIORGI (2009) Risorse linguistiche per la comunicazione nel settore del turismo. Roma: Carocci editore, 427-439. Dostopno na naslovu: http:// eprints.uniss.it/7159/1/Hoehmann_D_Risorse_linguistiche_per_comunicazione.pdf. http://www.academia.edu/7649848/IL_NUOVO_TURISMO_E_IL_MARKETING_

TERRITORIALE_RISORSE_LOCALI_PER_SFIDE_GLOBALI.

http://www.slovenia.info/?ps_analize_socialmedia $=3347 \& \operatorname{lng}=1$

http://www.slovenia.info/si/Strate\%C5\%A1 ki-forum-Bled-2016-Panel-Turizem. htm?bsf2016=0\&lng=1)

MARENTIČ POŽARNIK, B./ L. PLUT PREGELJ (2009) Moč učnega pogovora. Ljubljana: DZS, str. 19

Slovenska turistična organizacija. Strateški forum Bled 2016 - Panel Turizem. 6. september 2016. (citirano 10.9.2016). Dostopno na naslovu:

Slovenska turistična organizacija. Turizem v Sloveniji 2015. 27. junij 2016. (citirano 4.9.2016). Dostopno na naslovu: http://www.slovenia.info/?ps_najpomembnejsi-kazalniki $=3303 \& \operatorname{lng}=1$ 
SPIRIT Slovenija, javna agencija Republike Slovenije za spodbujanje podjetništva, internacionalizacije, tujih investicij in tehnologije. Ad hoc raziskava na spletnih družbenih omrě̌jih-Percepcija Slovenije s strani italijanskih turistov. November 2014. (Citirano 7.9.2016). Dostopno na naslovu:

ŠULIGOJ, B. (2016) Taleb Rifai: Potovanje je jezik miru. Delo, 07.09.2016, str. 2 VERTICCHIO, G., Il nuovo turismo e il marketing territoriale risorse locali per sfide globali. (Citirano 1.9.2016). Dostopno na naslovu:

\section{POVZETEK}

Spoznavanje Slovenije kot turistične destinacije je za italijanskega gosta neizogibno povezano s spoznavanjem gastronomije. Pri pripadnikih naroda, ki tako zavzeto goji kulturo hrane, je gastronomska ponudba $\mathrm{v}$ določenem okolju in času $\mathrm{v}$ mnogih primerih osnova za celovito dojemanje nekega območja.

Dobra ponudba, primerno trženje in dopadljiva predstavitev tipičnih slovenskih jedi imajo pomembno vlogo pri spoznavanju narodne in kulturne dediščine, saj imajo moč širiti nova spoznanja o krajih in ljudeh, odpravljati predsodke in krepiti medkulturno sodelovanje. Prijaznost in strokovna usposobljenost osebja, poznavanje jezika ter civilizacijskih in kulturoloških navad in razlik pa so lahko tisti dejavniki, ki pomagajo uveljavljati lastne izdelke in storitve ter vzgajati in izobraževati uporabnika gostinskih in turističnih storitev.

Ključne besede: gastronomija, turizem, jezik, izpopolnjevanje, zadovoljstvo gostov

\section{ABSTRACT}

\section{Communication of Slovenian Tourism Workers with Italian guests}

For an Italian guest, getting to know Slovenia as a tourist destination is inevitably connected with getting to know the Slovenian cuisine. Italians are a nation eagerly developing the culture of food, and therefore the gastronomic offer in a certain environment and at a certain time is for them often the basis for a comprehensive perception of the said destination.

A good offer, a suitable marketing and an attractive presentation of typical Slovenian dishes play an important role in getting to know natural and cultural heritage as they can widen the knowledge about people and places, eliminate prejudice and strengthen intercultural cooperation. Kind and professional staff, knowledge of the language, civilisation, cultural habits, and differences may be the factors contributing to the assertion of local products and services, and to educating the users of restaurant and tourism services.

Key words: gastronomy, tourism, language, training, customer satisfaction 